\title{
Audit on the Management of Bronchiolitis: A Single Centre Real World Experience in Bangladesh Can We do Better?
}

\author{
Farzana Hamid ${ }^{1 *}$ \\ Syed Moosa M A Quaium' \\ Azizur Rahman \\ A T Reza Ahmad \\ Shahariar Khan' \\ Tania Hussain' \\ Fatematuz Zahra
}

'Department of Paediatrics North East Medical College Sylhet, Bangladesh.
${ }^{*}$ Correspondence to:

\section{Dr. Farzana Hamid}

Associate Professor

Department of Paediatrics

North East Medical College, Sylhet, Bangladesh.

Mobile : +88 01815474442

Email: drfarzanahamid@yahoo.com

http://www.banglajol.info/index.php/CMOSHMCJ

\begin{abstract}
Background: Bronchiolitis is the most common reason for hospitalization of children in many countries.Though Respiratory Syncytial Virus (RSV) is the most common organism causing bronchiolitis, but antibiotics are used widely.So the aim of the present study is to establish whether antibiotic has any role in bronchiolitis management along with supportive treatment. Methods:This retrospective study included 100 infants and children between 2-24 months of age admitted with clear cut sign symptoms of bronchiolitis. Patients were divided into Group A (supportive + antibiotic Rx) comprised 72 patients and group B (supportive Rx only) comprised 28 patients.After 3-5 days of hospital stay, clinical responses were evaluated in terms of improvement in symptoms and clinical parameters- respiratory rate, heart rate and oxygen saturation. Results: Mean age of patients was $6.6( \pm 5.6)$ months in Group A and $6.3( \pm 4.8)$ months in Group B. Most of the patients in both study groups were male (M: $\mathrm{F}=1.6: 1)$. All the cases in both groups presented with cough, running nose, and respiratory distress. Fever and feeding difficulty were present in $83.3 \%$ \& $90.3 \%$ in Group A and $82.1 \%$ \& $89.3 \%$ in Group B respectively. Majority of cases were from lower socioeconomic status and lived in urban area. In Group A, after therapy mean respiratory rate $53.7( \pm 4.3)$ and oxygen saturation $97.9( \pm 1.9)$ had significantly improved in comparison to respiratory rate $65.6( \pm 4.8)$ and oxygen saturation 89.7 $( \pm 4.4)$ before therapy $(\mathrm{p}=<.001$ in all parameter). Heart rate also significantly increased after therapy $(149.4 \pm 10.2$ versus $104.5 \pm 8.7)(\mathrm{p}=<.001)$. In Group B, after therapy mean respiratory rate $53.5( \pm 4.1)$ and oxygen saturation $97.8( \pm 1.7)$ had also significantly improved in comparison to respiratory rate $65.3( \pm 4.1)$ and oxygen saturation $88.8( \pm 2.8)$ before therapy $(\mathrm{p}=<.001$ in all parameter). Heart rate also significantly increased after therapy $(150.8 \pm 9.8$ versus $105.0 \pm 6.2)(p=<.001)$. In comparison between two modalities of treatment, no significant difference was found ( $p$ value $=>.05$ in all parameters). No statistical significant difference was observed in the length of hospital stay in two groups. Conclusion: The study highlighted the importance of supportive treatment in bronchiolitis management. Antibiotics should not be used without clinical and laboratory evidence of bacterial infection.
\end{abstract}

Key words: Bronchiolitis; Respiratory syncytial virus; Adrenaline; Salbutamol; Antibiotic.

\section{INTRODUCTION}

Bronchiolitis is an acute lower respiratory tract infection in early childhood characterized by acute inflammatory injury of bronchioles. ${ }^{1}$ A substantial proportion of children will experience at least one episode with bronchiolitis, and as much as 2$3 \%$ of all children will be hospitalized with bronchiolitis during their first year of life $^{2}$. The most common pathogen is respiratory syncytial virus.Other pathogens include rhino virus, human metapneumovirus, parainfluenza virus, influenza virus, adenovirus, mycoplasma pneumonae. 
Bronchiolitis usually affects children younger than 2 years, with a peak in infants aged 3-6 months. Infants younger than 6 months are most severely affected, owing to their smaller, more easily obstructed airways and their decreased ability to clear secretions $^{2,3}$. Bronchiolitis occurs as much as 1.25 times more frequently in males than in females, the exact reason for this difference is unknown ${ }^{4-6}$. Risk factors for the development of bronchiolitis include low birth weight, particularly premature infants, lack of breast feeding, lower socioeconomic group, crowded living conditions, parental smoking, chronic lung disease, particularly bronchopulmonary dysplasia, congenital heart disease, congenital or acquired immune deficiency diseases $^{7,8}$.

Recognizing the pathologic picture that occurs in the airways of children with bronchiolitis is important in understanding the clinical manifestations and developing rational management. The viral infection occurs through the upper respiratory tract and spreads lower within a few days, resulting in inflammation of the bronchiolar epithelium, with peribronchial infiltration of white blood cell types, mostly mononuclear cells, and edema of the submucosa and adventitia. Plugs of sloughed, necrotic epithelium and fibrin in the airways cause partial or total obstruction to airflow. A "ball-valve" mechanism can result in trapping of air distal to obstructed areas, with subsequent absorption, atelectasis, and a mismatch of pulmonary ventilation and perfusion that may lead to hypoxemia ${ }^{3,6,7,8}$.

The diagnosis of bronchiolitis is based on clinical presentation, the patient's age, seasonal occurrence, and findings from the physical examination ${ }^{5}$. Hypoxia is the best predictor of severe illness and correlates best with the degree of tachypnea. No routine diagnostic tests except for pulse oxymetry, have been shown to have a substantial impact on the clinical course of bronchiolitis, and recent guidelines and evidence-based reviews recommend that no diagnostic tests are used routinely ${ }^{5,9}$. Tests are typically used to exclude other diagnoses (eg, bacterial pneumonia, sepsis, or congestive heart failure) or to confirm a viral etiology ${ }^{10}$.

Treatment of bronchiolitis is directed toward symptomatic relief and maintenance of hydration and oxygenation. Medical therapies used to treat bronchiolitis in infants and young children are controversial ${ }^{11}$. Although numerous medications and interventions have been used to treat bronchiolitis, at present, only oxygen appreciably improves the condition of young children with bronchiolitis ${ }^{9}$. Bronchodilatorsare commonly used in practice, though convincing evidence is absent. However, a clinically important, significant effect has been documented for neither adrenaline nor beta-2agonists $^{11,12}$. Corticosteroids have not clearly been shown to be of significant benefit in improving the clinical status of patients with bronchiolitis.However, in some countries they are used routinely ${ }^{13}$. Antibiotic is commonly used in children with bronchiolitis, but should not be indicated unless bacterial infection is suggested ${ }^{15-18}$.
This audit was conducted to establish whether antibiotic has any role in bronchiolitis management along with supportive treatment and to help in formulating an institution based practical guideline for the practitioners to improve clinical outcome.

\section{MATERIALS AND METHODS}

This retrospective study was carried out at North East Medical College Hospital over a period of 10 months from October 2013 to July 2014. Previously healthy 2 months to 24 months old infants and children diagnosed as bronchiolitis clinically on the basis of history (fever, running nose, cough, respiratory distress \& feeding difficulty) and physical examination (tachypnoea, tachycardia, fine crepitation, rhonchi) were included in the study. Highly febrile toxic patients with evidence of pneumonia, known case of asthma or congenital heart disease were excluded from the study. Oxygen saturation was measured using pulse oxymeter, and those with values less than $92 \%$ were considered as having significant hypoxia. We analyze the admission charts of 100 patients fulfilling the inclusion criteria. Records retrieved from the charts were entered into prepared proforma, which included the information regarding age, sex, risk factors, common clinical features, treatment options, and length of hospital stay.

Patients were divided into two groups. Group A comprised 72 patients, where as Group B comprised 28 patients. Both groups received supportive treatment which included oxygen inhalation, hydration, nutrition, antipyretic for temperature $100^{\circ} \mathrm{F}$, nebulized salbutamol and occasional steroid.On the top of it, Group A received oral or intravenous antibiotics based on the severity.Patients were followed up daily.After 3-5 days of hospital stay, clinical responses were evaluated in terms of improvement in symptoms andclinical parameters- respiratory rate, heart rate and oxygen saturation.

Data were processed and analyzed by using SPSS statistical software version 20 employing appropriate statistical tests. Any probability value of less than .05 was considered statistically significant.

\section{RESULTS}

The study included 72 cases in Group A (supportive + antibiotic Rx) and 28 cases in Group B (supportive Rx only). Mean age of patients was $6.6( \pm 5.6)$ months in Group A and 6.3 $( \pm 4.8)$ months in Group B. Most of the patients in both study Groups were male (M: F=1.6:1). Majority 45(62.5\%) in Group A and 17(60.7\%) in Group B were exclusively breastfed up to 6 months of age. 30(41.7\%) in Group A and 10(35.7\%) in Group $\mathrm{B}$ were exposed to passive smoking. Most of the patients in both groups were from lower middle class family. 69.4\% in Group A and 67.9\% in Group B lived in urban area. 
Table 1 : Distribution of patients by age

\begin{tabular}{cc}
\multicolumn{3}{c|}{ Age in months } \\
$\begin{array}{c}\text { Group A }(\mathbf{n}=72) \\
\text { Mean } \pm \text { SD }\end{array}$ & $\begin{array}{c}\text { Group B }(\mathbf{n}=\mathbf{2 8}) \\
\text { Mean } \pm \text { SD }\end{array}$ \\
$6.6( \pm 5.6)$ & $6.3( \pm 4.8)$ \\
\hline
\end{tabular}

Figure 1: Distribution of patients according to sex

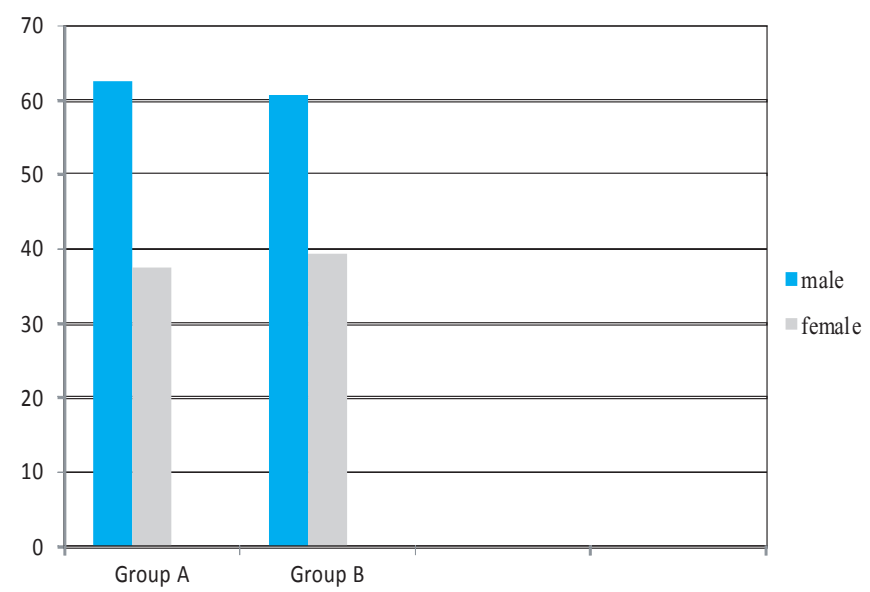

Table 2 : Distribution of risk factors in Group A \& Group B

$\begin{array}{|lcc|}\begin{array}{l}\text { Risk factor } \\ \text { EBF (6 months) }\end{array} & \begin{array}{r}\text { Group A (n=72) } \\ \text { Percentage (\%) }\end{array} & \begin{array}{c}\text { Group B (n=28) } \\ \text { Yes }\end{array} \\ \text { No } & 45(62.5) & 17(60.7) \\ \text { Passive Smoking } & 27(37.5) & 11(39.3) \\ \text { Present } & 30(41.7) & 10(35.7) \\ \text { Absent } & 42(58.3) & 18(64.3) \\ \text { Socioeconomic Status } & & \\ \text { Lower middle } & 41(57.0) & 18(64.3) \\ \text { Middle class } & 31(43.0) & 10(35.7) \\ \text { Residence Urban } & 50(69.4) & 19(67.9) \\ \text { Rural } & 22(30.6) & 09(32.1)\end{array}$

Table 3: Clinical presentation of patients with bronchiolitis

\begin{tabular}{lcc} 
Clinical Presentation & $\begin{array}{c}\text { Group A }(\mathrm{n}=\mathbf{7 2}) \\
\text { Percentage }(\%)\end{array}$ & $\begin{array}{c}\text { Group B }(\mathrm{n}=\mathbf{2 8}) \\
\text { Fever }\end{array}$ \\
Cough & $68(83.3)$ & $23(82.1)$ \\
Respiratory distress & $72(100)$ & $28(100)$ \\
Running nose & $72(100)$ & $28(100)$ \\
Feeding difficulty & $72(100)$ & $28(100)$ \\
\hline
\end{tabular}

All the cases in both groups presented with cough, running nose, and respiratory distress. Difficulty of feeding was a presenting feature in $65(90.3 \%)$ patients of Group A and 25 $(89.3 \%)$ patients of Group B. $83.3 \%$ \& $82.1 \%$ patients presented with fever in Group A and Group B respectively.In Group A, after therapy mean respiratory rate $53.7( \pm 4.3)$ and oxygen saturation $97.9( \pm 1.9)$ had significantly improved in comparison to respiratory rate $65.6( \pm 4.8)$ and oxygen saturation $89.7( \pm 4.4)$ before therapy $(p=<.001$ in all parameter). Heart rate also significantly increased after therapy (149.4 \pm 10.2 versus $104.5 \pm 8.7)(\mathrm{p}=<.001)$. In Group B, after therapy mean respiratory rate $53.5( \pm 4.1)$ and oxygen saturation $97.8( \pm 1.7)$ had also significantly improved in comparison to respiratory rate $65.3( \pm 4.1)$ and oxygen saturation $88.8( \pm 2.8)$ before therapy $(\mathrm{p}=<.001$ in all parameter $)$. Heart rate also significantly increased after therapy $(150.8 \pm 9.8$ versus 105.0 $\pm 6.2)(p=<.001)$. In comparison between two modalities of treatment, no significant difference was found ( $\mathrm{p}$ value $=>.05$ in all parameters). Mean hospital stay in Group A was $4.2( \pm 1.1)$ days, while in Group B was $3.9( \pm 1.0)$ days which was also not statistically significant $(\mathrm{p}=.06)$.

Table 4 : Comparison of response to therapy between Group A \& Group B

\begin{tabular}{|c|c|c|c|c|c|}
\hline \multirow[b]{2}{*}{ Parameter } & \multicolumn{2}{|c|}{ Before therapy } & \multicolumn{3}{|c|}{ After therapy } \\
\hline & $\begin{array}{c}\text { Group A } \\
(\mathrm{n}=72) \\
\text { Mean }( \pm \mathrm{SD})\end{array}$ & $\begin{array}{c}\text { Group B } \\
\quad(n=28) \\
\text { Mean ( } \pm \text { SD) }\end{array}$ & P. value & $\begin{array}{c}\text { Group A } \\
(n=72) \\
\text { Mean }( \pm \text { SD) }\end{array}$ & $\begin{array}{l}\text { Group B P. value } \\
(n=28) \\
\text { Mean }( \pm \text { SD) }\end{array}$ \\
\hline Respiratory rate & $65.6( \pm 4.8)$ & $65.3( \pm 4.1)$ & 24 & $53.7( \pm 4.3)$ & $53.5( \pm 4.1) \quad .13$ \\
\hline Heart rate & $104.5( \pm 8.7)$ & $105.0( \pm 6.2)$ & .38 & $149.4( \pm 10.2)$ & $150.8( \pm 9.8) \quad .22$ \\
\hline $\begin{array}{l}\text { Oxygen } \\
\text { saturation }\end{array}$ & $89.7( \pm 4.4)$ & $88.8( \pm 2.8)$ & .17 & $97.9( \pm 1.9)$ & $97.8( \pm 1.7) \quad .12$ \\
\hline
\end{tabular}

Table 5 : Relationship of post treatment hospital stay between Group A \& Group B

\begin{tabular}{|ccc|}
\hline $\begin{array}{c}\text { Study in Hospital } \\
\text { Group A }(\mathbf{n}=\mathbf{7 2}) \\
\text { Mean }( \pm \text { SD) }\end{array}$ & $\begin{array}{c}\text { Group B }(\mathbf{n}=\mathbf{2 8}) \\
\text { Mean }( \pm \text { SD) }\end{array}$ & P. value * \\
\hline $4.2( \pm 1.1)$ & $3.9( \pm 1.0)$ & .06 \\
\hline
\end{tabular}

*Paired sample T test was employed to analyze the data.

\section{DISCUSSION}

The present study included 72 cases in Group A (Supportive + antibiotic Rx) and 28 cases in Group B (Supportive Rx only). In this study, mean age of patients in Group A was $6.6( \pm 5.6)$ months and in Group B was $6.3( \pm 4.8)$ months. Studies in infants below 12 months of age from the USA have found increasing rates of bronchiolitis (188/1000 infants in 1996/97 to $265 / 1000$ in $2002 / 03)^{1.2}$. In a prospective hospital based study from Southern India, of 114 children with bronchiolitis, $87(76 \%)$ were less than 1 year and 107 (94\%) were lessthan 2 years of age $^{3}$. In another Indian study, mean age was 5.6 months ${ }^{4}$. 
Present study showed 45 (62.5\%) male and 27 (37.5\%) female in Group A, while 17(60.7\%) male and 11(39.3\%) female in Group B. Similar male preponderance was reported by different studies $^{4,5,6}$. Majority cases in both groups were exclusively breast fed up to 6 months. Though breast feeding has a protective effect against infection, the present study showed that breast fed babies also suffered with bronchiolitis. In Group A, passive smoking was noted in $41.7 \%$ family members versus $35.7 \%$ in Group B. Majority of the family members were non smoker in both groups, though smoking is a recognized risk factor for bronchiolitis, particularly maternal smoking ${ }^{7}$. Most of the patients were from poor socioeconomic condition in our study. Here urban children were affected more. These results were supported by previous study ${ }^{8}$.

In this study, running nose, cough and respiratory distress were present in $100 \%$ cases in both groups. Feeding difficulty was a presenting feature in $65(90.3 \%)$ cases in Group A and 25 $(89.3 \%)$ cases in Group B. Almost similar percentage of patients in both groups presented with fever (up to $101^{\circ} \mathrm{F}$ ). Two studies from Bangladesh observed the same clinical patterns similar to our study ${ }^{5,9}$.

Comparing Group A (Supportive + antibiotic Rx) with Group B (Supportive Rx only), we noticed significant improvement of respiratory rate and oxygen saturation after therapy in both groups, but the difference of improvement while we compared between the two groups after 3-5 days of treatment was statistically not significant.In a meta-analysis of 28 trials (1912 participants) comparing bronchodilators with placebo, there were no significant difference in improvement in oxygenation, hospitalization rate, or duration of hospitalization. A modest improvement in clinical scores was noted in the treated outpatients; however, this small improvement in clinical scores must be weighed against the costs and adverse effects of bronchodilators ${ }^{10}$. A 2006 Cochrane systematic review of studies that compared bronchodilators for the management of bronchiolitis in outpatients suggested a potential benefit with epinephrine administration ${ }^{11}$. Another study of 703 children with bronchiolitis compared 3 doses of albuterol with 1 dose of racemic epinephrine and revealed a small benefit that favored albuterol in successful discharge. ${ }^{12}$ In a study, both nebulized salbutamol and adrenaline were useful in relieving symptoms \& improving oxygenation, but comparatively nebulized adrenaline was superior to nebulized salbutamol in bronchiolitis ${ }^{9}$.

In the present study, some patients received corticosteroid, though corticosteroid administration for the treatment of bronchiolitis also has been controversial. A multicenter trial from the Pediatric Emergency Care Applied Research Network, which enrolled 600 previously healthy infants with a first episode of bronchiolitis, showed that a single oral dose of dexamethasone resulted in no significant improvement compared with placebo in the rate of hospitalization or clinical scores ${ }^{13}$. Nebulized hypertonic saline has been associated with improvement in clinical score and duration of hospitalization in recent randomized trials though our patients did not receive $i^{14}$.
In the present study, 72 patients in Group A received antibiotic either oral or intravenous along with supportive treatment. In comparison between two modalities of treatment (with or without antibiotic along with supportive $\mathrm{Rx}$ ), no significant difference was found ( $\mathrm{p}$ value $=>.05$ in all parameters). Similar results were reported by some other studies. A systematic review including five studies (543 participants) did not find significant benefits for use of antibiotics in acute bronchiolitis. However, the review indicated a need for research to identify a sub group of patients who may benefit from antibiotics ${ }^{15}$. One small study (21 participants) which was included in this review, compared clarithromycin for 3 weeks with placebo in children with RSV bronchiolitis. Treatment with clarithromycin was associated with reduction in the length of hospital stay, duration of need for oxygen, and readmission rates. Clarithromycin was proposed to have a possible immunomodulatory effect. More well planned studies to clarify role of macrolides in acutebronchiolitis are required ${ }^{16}$. In children with bronchiolitis and fever, the risk of secondary bacterial infection is low, therefore, routine use of antibiotics is not warranted. It is recommended that antibiotics should be used only in children having specific indications of coexistence of a bacterial infection ${ }^{17}$. However, antibiotics may more frequently be needed due to concurrent bacterial infections in infants with severe disease, especially those requiring mechanical ventilation $^{18}$.

Current study showed mean hospital stay in Group A was 4.2 $( \pm 1.1)$ days, while in Group B was $3.9( \pm 1.0)$ days. The difference of the length of hospital stay between two groups was not statistically significant ( $p$ value .06), which correlated with other studies ${ }^{19,20}$.

\section{CONCLUSION}

The study concluded that antibiotic has no role in improving clinical sign symptoms in patients with bronchiolitis. Antibiotics are not indicated unless bacterial infection is suggested (eg, by a toxic appearance, hyperpyrexia, consolidation or focal lobar infiltrates on chest radiography, leukocytosis, or positive bacterial cultures). Thus, administration of broad-spectrum antibiotics in critically ill infants is often justified until culture results prove negative. The decision to start antibiotics should be made on a case-bycase basis because unnecessary use of antibiotics is associated with increased cost of treatment, adverse reactions and development of bacterial resistance in community.

\section{LIMITATION OF THE STUDY}

Multicentre study is still needed to strengthen the evidence in treating bronchiolitis patients.

\section{RECOMMENDATION}

1. Based on present study as well as previous studies, we should formulate a national and institution based guideline and protocol to improve the outcome.

2. Paediatricians should follow the evidence based practice more than short scale personal experience and pre occupied ideas and belief.

\section{DISCLOSURE}

All the authors declared no competing interest. 


\section{REFERENCES}

1. Wainwright C.Acute viral bronchiolitis in children- a very common condition with few therapeutic options. PaediatrRespir Rev. 2010, 11:39-45

2. Carroll KN, Gebretsadik T, Griffin MR, Wu P, Dupont WD, Mitchel EF, et al. Increasing burden and risk factors for bronchiolitisrelated medical visits in infants enrolled in a state health care insurance plan. Pediatrics.2008, 122:58-64.

3. Cherian T, Simoes EA, Steinhoff MC, Chitra K, John M, Raghupathy P, et al. Bronchiolitis in tropical South India. Am J Dis Child.1990; 144:1026-1030.

4. Ray MS, Singh V. Comparison of nebulized adrenaline versus salbutamol in wheeze associated respiratory tract infection in infants. Indian Pediatr.2002; 39:12-22

5. Kabir ARML, Haq N, Hoque M, Ahmed F, Amin R, Hossain A, et al. Evaluation of hospital infants and young children with bronchiolitis- a multicentre study. Mymensingh Medical Journal.2003; 12:128-133.

6. Iwane MK, Edwards KM, Szilagyi PG, Walker FJ, Griffin MR, Weinberg GA. Population-based surveillance for hospitalizations associated with respiratory syncytial virus, influenza virus, and parainfluenza viruses among young children. Pediatrics.2004; 113(6):1758-1764.

7. Carroll KN, Gebretsadik T, Griffin MR. Maternal asthma and maternal smoking are associated with increased risk of bronchiolitis during infancy. Pediatrics. 2007; 119(6):1104-1112.

8. Meissner HC. Selected populations at increased risk from respiratory syncytial viral infection.Pediatric Infectious Disease.2003; 22:40.

9. Morshed AKMA, Amin MR. Comparative efficacy of Nebulized L adrenaline versus salbutamol in infants with acute bronchiolitis. Bangladesh J Child Health. 2008; 32(1):10-16.

10. Gadomski AM, Brower M. Bronchodilators for bronchiolitis. Cochrane Database Syst Rev.2010; 12:CD001266.

11. Hartling L, Wiebe N, Russell K, Patel H, Klassen TP. Epinephrine for bronchiolitis. Cochrane Database SystRev. 2004 ; (1):CD003123.

12. Walsh P, Caldwell J, McQuillan KK, Friese S, Robbins D, Rothenberg SJ. Comparison of nebulized epinephrine to albuterol in bronchiolitis.AcadEmerg Med. 2008; 15(4):305-313.

13. Corneli HM, Zorc JJ, Majahan P. A multicenter, randomized, controlled trial of dexamethasone for bronchiolitis. N Engl J Med. 2007; 357(4):331-339.

14. Kuzik BA, Al-Qadhi SA, Kent S. Nebulized hypertonic saline in the treatment of viral bronchiolitis in infants. J Pediatr. 2007; 151(3):266-270.

15. Spurling GK, Doust J, Del Mar CB, Eriksson L. Antibiotics for bronchiolitis in children. Cochrane Database Syst Rev. 2011; 6:CD005189.

16. Tahan F, Ozcan A, Koc N. Clarithromycin in the treatment of RSV bronchiolitis: a double-blind, randomised,placebo-controlled trial. EurRespirJ. 2007; 29:91-97.

17. American Academy of Pediatrics Subcommittee on Diagnosis and Management of Bronchiolitis.Diagnosis and management of bronchiolitis.Pediatrics.2006; 118:1774-1793.

18. Thorburn K, Harigopal S, Reddy V, Taylor N, van Saene HK. High incidence of pulmonary bacterial co-infection in children with severe respiratory syncytial virus bronchiolitis. Thorax.2006, 61:611-615.

19. Mussman GM, Parker MW, Statile A, Sucharew H, Brady PW. Suctioning and Length of Stay in Infants Hospitalized with Bronchiolitis. JAMA Pediatr.2013; 1-8.

20. Mansbach JM, Piedra PA, Teach SJ. Prospective multicenter study of viral etiology and hospital length of stay in children with severe bronchiolitis. Arch PediatrAdolesc Med. 2012; 166:700. 